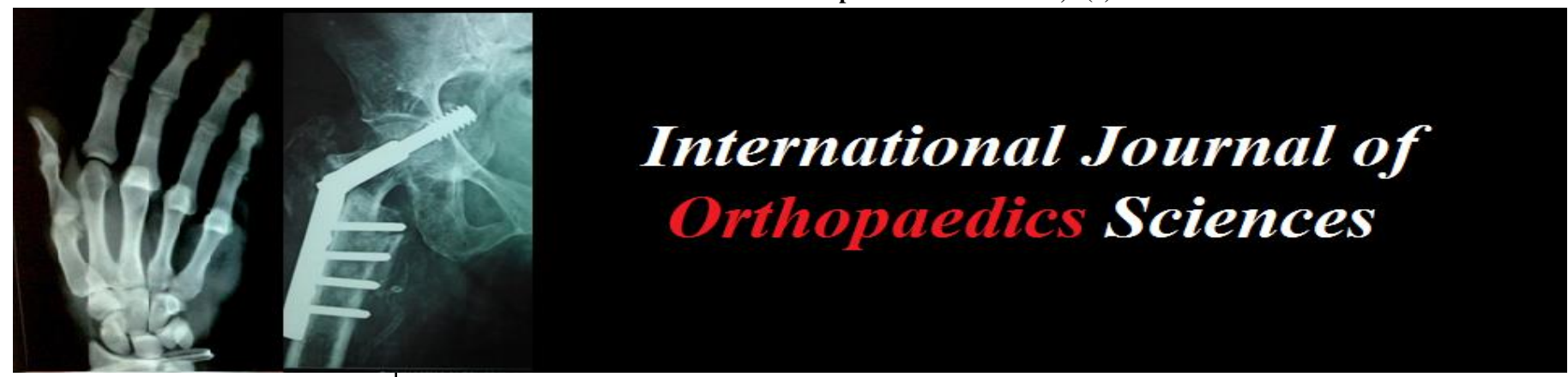

ISSN: $2395-1958$

IJOS 2019; 5(1): 328-332

(C) 2019 IJOS

www.orthopaper.com

Received: 18-11-2018

Accepted: 23-12-2018

\section{Pandey Anil}

Investigation Performed at Department of Orthopedics, Gandhi Medical College and Hamidia Hospital, Bhopal, Madhya Pradesh, India

Dr. Chouhan Shailendra Assistant Professor, Government Medical, College, Khandwa, Madhya Pradesh, India

Maravi Deepak S

Investigation Performed at Department of Orthopedics, Gandhi Medical College and Hamidia Hospital, Bhopal, Madhya Pradesh, India

Uikey S

Investigation Performed at Department of Orthopedics, Gandhi Medical College and Hamidia Hospital, Bhopal, Madhya Pradesh, India
Correspondence

Dr. Chouhan Shailendra

Assistant Professor, Government

Medical, College, Khandwa,

Madhya Pradesh, India

\section{Comparative analysis of closed reduction and expert tibia nailing and open reduction and plate $\&$ screw fixation in the treatment of proximal tibia extraarticular fractures}

\author{
Pandey Anil, Dr. Chouhan Shailendra, Maravi Deepak S and Uikey S
}

DOI: https://doi.org/10.22271/ortho.2019.v5.i1f.59

\begin{abstract}
Introduction: Extra-articular proximal tibial fractures account for 5-10\% of all tibial shaft fractures and it result from high-velocity trauma. Closed reduction with minimally invasive plating and locked intramedullary nailing have been widely used for treatment of proximal tibia extraarticular fractures. Our pupose is to compare the pros and cons of these two methods.

Materials and Methods: 22 patients were included in this study for a period of 2 years. Patients treated with IMN were kept in group A patients treated with percutaneus plating were kept in group B. Standard approach of nailing and plating were used and proper follow up were taken for next upcoming 1 year.

Results: Combined average age was 38years. Male were more commonly affected than female (13:8). Majority of fracture were of type A33. Operative time was $<2$ hours in both groups. Less blood loss occurred during intramedullary nailing as compared to locking plate fixation. Surgical site infections (SSIs) were seen in two patients in the PTP group. Delayed union occurred in two patients in the IMN group. The average range of motion was 119.7 (range $90-150, \mathrm{SD}=19.18$ ) in group A and 115.2(range $80-150, \mathrm{SD}=17.28$ ) in group $\mathrm{B}$.

Conclusion: In treatment of proximal tibia extra articular fracture use of IMN and PTLCP gives comparable results. To validate this issue further a large sample size multicentric study is recommended.
\end{abstract}

Keywords: Intramedullary nailing (IMN), extraarticular tibialn fracture, surgical site infection

\section{Introduction}

Extra-articular proximal tibial fractures account for 5-10\% of all tibial shaft fractures ${ }^{[1,2]}$ and It result from high-velocity trauma. They lead to complex tissue injuries of bone and surrounding soft tissues [1]. If Conservative management of these fractures has resulted in malunion, nonunion, rotational deformity, or stiffness of adjacent joints ${ }^{[3,4]}$. So there has shift towards operative management of these fractures in recent times. However, surgically treating these fractures remains debatable. Options include half-pin external fixation, intramedullary implant, hybrid or thin-wire external fixation, plate fixation, or a combination of these techniques ${ }^{[5]}$.

In recent years, closed reduction with minimally invasive plating and locked intramedullary nailing have both become widely used treatment modalities for proximal tibia extraarticular fractures ${ }^{[7,8]}$. We design to this study intended to compare these options in terms of operative time, duration of hospital stay, period of non-weight bearing, degree of reduction, union rate, malunion rate, infection rate, and rates of other possible complications which could possibly affect decision-making in relation to such fracture patterns.

\section{Materials and Methods}

22 patient of Gandhi Medical College and Hamidia Hospital Bhopal were included in this study during the study period of 2 years. Patients were followed up for 1year, evaluated radiologically and clinically with Tegnerlysholm knee scale, $\mathrm{t}$ outcomes were used for comparison. Skeletally matured (age group 18-65 years) having closed Proximal one third tibia extraarticular fracture (defined as roughly to proximal $30 \%$ of the entire tibia.) 
Were included in this study. Intraarticular fracture, pathological fracture, fracture with vascular complications were excluded.

Group a patients were treated with IMN and group B patients received percutaneous tibia plating. In group $\mathrm{A}$ the patient was positioned supine on the operation table. Temporary anatomical reduction was achieved by closed manipulation before nailing. An incision by splitting patellar tendon extending from lower pole of patella to tibial tuberocity was used to open the joint. Antero-posterior or medio-lateral blocking screws were also used only in few cases. The surgical wound closure was done in layers. The intramedullary nail had a proximal Herzog band and four multilevel, multiplanar, and multidirectional screws (Fig 1). In group B using curvilinear incision over the lateral aspect of the proximal tibia. Indirect reduction was achieved using axial traction and/or the application of a reduction clamp or distractor. Internal fixation was then achieved with a proximal tibial lateral locking compression plate (LCP). A minimum of three screws were used on both sides of the fracture, and plating was done using a minimally invasive technique (Fig.
2).

Postoperatively, patients of both groups were given i.v third generation cephalosporins for 5days. Ankle pumps and isometric quadriceps strengthening exercises were started on the first postoperative day, followed by active and assisted knee bending and partial weight bearing started on the second Postoperative day depend on stability construct whereas full weight-bearing was allowed after complete clinical and radiological union. Patients were followed up at 2 and 6 weeks, 3 and 6 months, and 1 year postoperatively.

Both the immediate postoperative and the final follow-up radiographs compared to assess the accuracy of reduction and final alignment. Measurements for coronal (varus and valgus) and sagittal (procurvatum and recurvatum) plane deformities using technique described by Freedman and Johnson ${ }^{[10]}$. In AP view, varus/valgus deformity evaluated by measuring the angle between the lines drawn perpendicular to the proximal and distal tibial articular surfaces. In lateral view, the procurvatum/recurvatum was measured similarly and 8 degree of posterior slope was subtracted. Malreduction was defined as a deformity of 5degree in any plane.

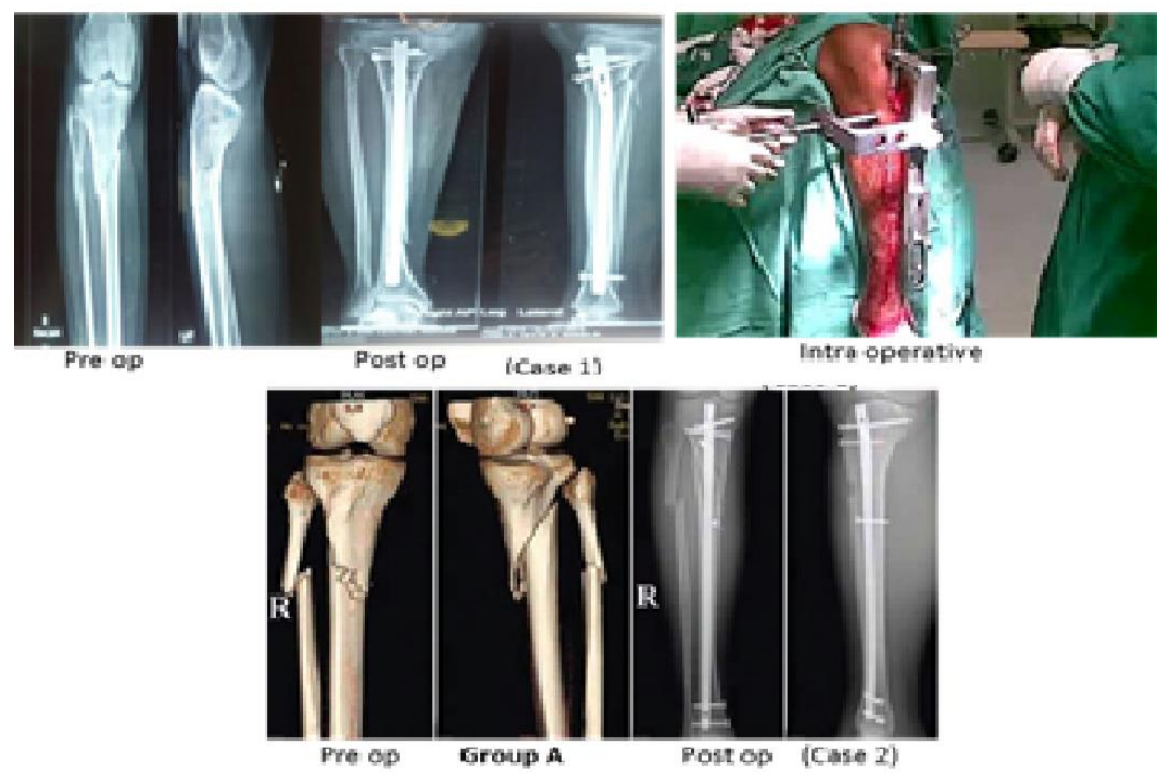

Fig 1: Pre-Operative, Intraoperative and post-operative pic of group "A"
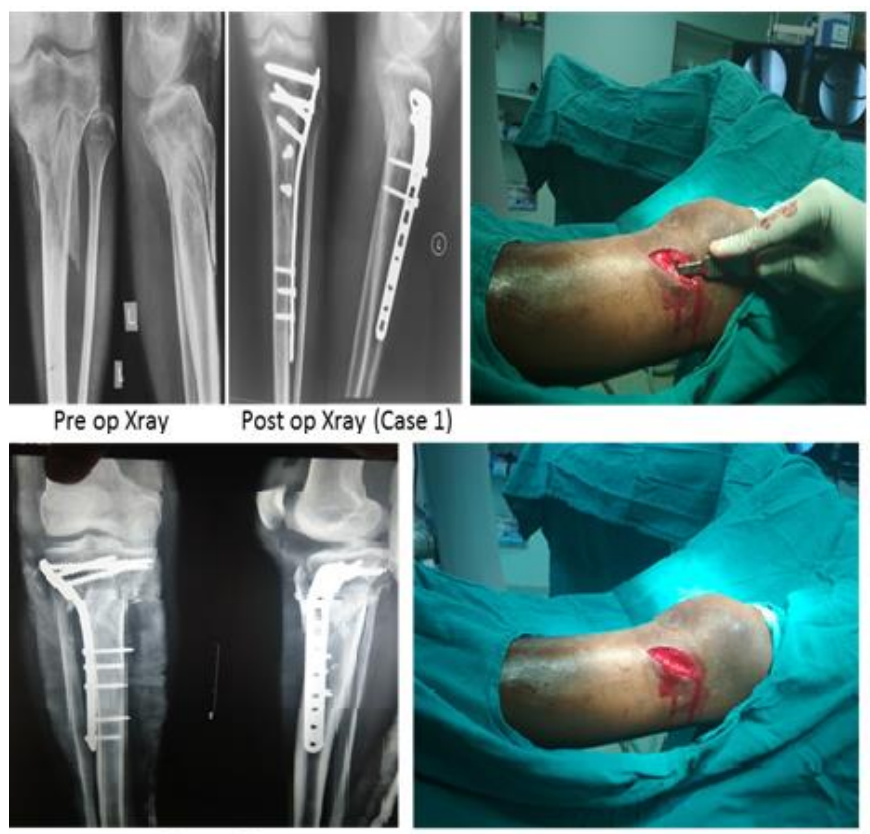

(Case 2) 


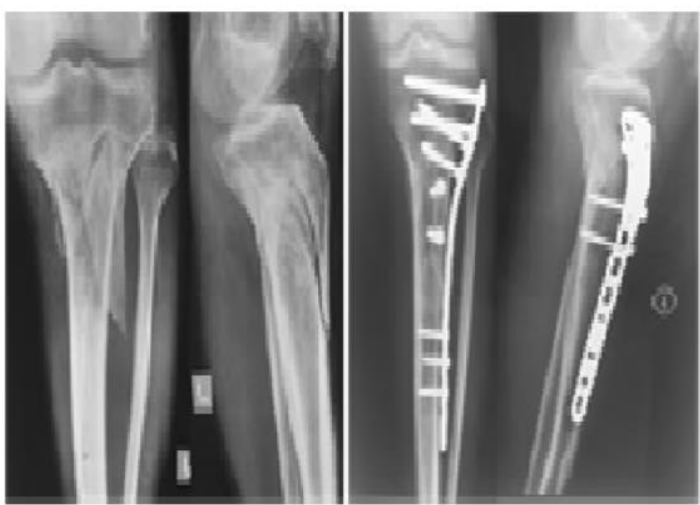

Fig 2: Pre-Operative, Intra operative and post-operative pic of group "B"

Out of a total of 22 patients, 01 ( 1 in the plating group) were excluded from the study as they were absent for follow-up, meaning that 21 patients were included in the final outcome analysis.

Table 1: Baseline data of 21 patients

\begin{tabular}{|c|c|}
\hline Parameter & N \\
\hline Injury cause & 8 \\
\hline Car accident & 6 \\
\hline Falling down & 5 \\
\hline Fall from height & 2 \\
\hline Others & 5 \\
\hline Fracture type & 16 \\
\hline Open & \\
\hline Close & 2 \\
\hline Combine injury & 1 \\
\hline Clavicle fracture & 0 \\
\hline Rib fracture &
\end{tabular}

All data were entered into a proforma. A stastistical analysis was performed by using the Statistical Package. The parameters were compared between the groups

Table 2: Comparison of the demographic and postoperative data for both groups

\begin{tabular}{|c|c|c|}
\hline Parameter & Group A & Group B \\
\hline Age (Average) & 39 year $(19-65)$ & 36 year $(19-62)$ \\
\hline \multicolumn{3}{|l|}{ Sex } \\
\hline Male & 8 & 5 \\
\hline Female & 6 & 2 \\
\hline \multicolumn{3}{|l|}{ Mode of trauma } \\
\hline Road traffic accident & 5 & 3 \\
\hline Fall from hight & 3 & 2 \\
\hline Falling down & 4 & 2 \\
\hline Other & 2 & 0 \\
\hline \multicolumn{3}{|l|}{ Fracture type extraarticular } \\
\hline $41 \mathrm{~A} 2$ & 3 & 5 \\
\hline 41A3 & 8 & 5 \\
\hline Injury operation interval (in days) & 7.4 & 7.06 \\
\hline Average operative time (in minutes) & 61.25 & 72.8 \\
\hline Open reduction & None & $47 \%$ \\
\hline Blood loss (average) & $50-100 \mathrm{ml}$ & $100-200 \mathrm{ml}$ \\
\hline Infection & 1 & 2 \\
\hline Nonunion & 1 & 0 \\
\hline Duration of hospital stay & $4.1(2-8)$ & $5.3(3-10)$ \\
\hline Union time (Weeks) & $18.26(10-30)$ & $22.84(16-34)$ \\
\hline Range of motion of knee & $119.7(90-150)$ & $115.2(80-150)$ \\
\hline Distribution of malunion & 2 & 0 \\
\hline Anterior angulation & 0 & 0 \\
\hline Posterior angulation & 0 & 0 \\
\hline Valgus malunion & 1 & 1 \\
\hline Varus malunion & & \\
\hline
\end{tabular}

\section{Results}

Extraarticular proximal tibial fracture was more common in age group between 19 to 65 years with the combined average age was 38years. Male was more commonly affected than female and $\mathrm{M}: \mathrm{F}$ ratio was 13:8. Young male are more involve in outside, productive, high energy activities so male more compatible suffer from this fracture. In both the group road traffic accident followed by fall from height was the two most common mode of trauma.

Classification of fracture: majority of fracture were of type A33, significant Comminution was present in these type of fractures.

Duration after injury, Most of the cases in both the group were operated within ten days of injury.

Operating time, in most of the cases $96.77 \%$ (60/62) operative time is $<2$ hours. One case in each group required more than 2 hour. According to data, PTLCP fixation takes more time than intramedullary fixation.

Blood loss, There was no heavy blood loss in any of the case, because all the fixations are done under tourniquet. Less blood loss occurred during intramedullary nailing as compared to locking plate fixation.

Postoperative hospital stay, time period to full weight bearing, and union time were significantly less in the IMN group as compared to the PTP group (Table 2).

Surgical site infections (SSIs) were seen in two patients in the PTP group, one of which was resolved with debridement while the other necessitated implant removal due to infection. Delayed union occurred in two patients in the IMN group, for which dynamization was performed by removing the distal screw.

Nonunion occurred in one case in the nailing group presented which ultimately required exchange nailing with bone grafting and fibular osteotomy. There was nonunion in one patient in the PTP group; bone grafting was done in that case, which eventually led to fracture healing.

Malalignment was seen in three patients $(21.1 \%)$ in the IMN group (one patient had varus and two had anterior apex deformity) and in one patients (16\%) in the PTP group (varus malalignment). Observe in immediate postoperative and 1year follow up Xray

The average range of motion was 119.7 (range $90-150, \mathrm{SD}=$ 19.18 ) in group $\mathrm{A}$ and 115.2 (range $80-150, \mathrm{SD}=17.28$ ) in group B. There were complaints of occasional anterior knee pain and discomfort upon kneeling on the floor from two patients in group A and two patients in group B.

\section{Discussion}

Proximal tibia extraarticular fractures often occur in people 
belonging to young active age group. In present study, the overall mean age was 38 years (range 19 to 65 years). Schultz M. et al. ${ }^{[11]}$ has shown mean age of 42 years in their study. While Cole, et al. ${ }^{[12]}$ have shown mean age of 45 years in their study. $90.3 \%$ of the patients in present study were male and only $9.7 \%$ were females. Thus results of present study were well similar with results of previous studies ${ }^{[11,12]}$.

In present study, road traffic accident was found to be the major cause of this fracture. In $80.6 \%$ of the cases, mode of trauma was road traffic accident and in $16 \%$ of the cases, mode of trauma was fall from height while $3.2 \%$ of the cases had history of assault by hard and blunt object. Various previous studies have also shown similar distribution of mode of injury ${ }^{[11,13]}$.

Lindval E. et al. ${ }^{[13]}$ have also shown high prevalence of 41A3 in their study. Most common type of fracture observed in present study was $41 \mathrm{~A} 3.77 .41 \%$.patients in study had $41 \mathrm{~A} 3$ type of fracture while rest $22.59 \%$ patients had 41A2 type of fracture. 41A3 fractures represent significant communition which requires a large amount force to occur.

In present study, the average injury operation delay was 7.23 days. In study of Cole et al. ${ }^{[9]}$ average, Poor soft tissue condition, associated medical illnesses, associated injuries, feasibility of implant and many other factors were responsible for this delay in fixation in present study.

There is no significant data available in literatures about the duration of surgery for both the treatment modality. In present study, most of the fixations were done within 2 hours. Proximal one third extraarticular fracture often fixed under tourniquet so no significant blood loss occurred intraoperatively.

Table 3: Comparison of Malunion in various study

\begin{tabular}{|c|c|c|c|}
\hline Study & Extra articular proximal tibia fracture & Malunion (>50 degree) & No. of cases of malunion \\
\hline Lange et al. ${ }^{[15]}$. & 32 & 23 & 16-apex ant. 13 valgus( 6 with both plane) \\
\hline Tornetta et al. ${ }^{[17]}$. & 30 & 7 & 4 apex ant. 3 coronal \\
\hline Nork et al. ${ }^{[16]}$ & $30-33$ & 3 & 1 Varus \\
\hline Lindvall et al. ${ }^{[13]}$. & 22 & 9 & 8 apex anterior 2 valgus \\
\hline Present Study & 14 & 3 & 2 anterior angulation 1 varus \\
\hline Cole et al. & 28 & 08 & 1 valgus 6 apex ant 1 apex posterior \\
\hline Ricci et al. & 18 & 05 & 2 valgus 2 apex ant. 1 apex post \\
\hline Lindvall et al. & 34 & 07 & 5 apex anterior with 1 varus 2 apex post. \\
\hline Vidhyadhar S. et al. & 45 & 07 & 4 apex anterior, 3 valgus \\
\hline Present study & 7 & 01 & 1 varus \\
\hline
\end{tabular}

In present the pooled rate of malunion was greater after intramedullary nailing $(3 / 14,21.4 \%)$ than after plating $(1 / 7$, $14.28 \%$ ).

Anterior curvature mal-alignment is encouraged by a tibial plateau that is directed posteriorly between $3^{\circ}$ to $7^{\circ}$ and also by the pull of the patellar ligament, inserted on to the tibial tuberosity ${ }^{[13]}$.

To avoid this complication in nailing of this type fracture, some specific additional techniques can be used. These include, adjusting the proximal starting point, nailing in semiextended position, using an adjuvant plate and placing blocking screw before nailing.

To avoid malunion complications in PTLCP fixation Oh C.W. et al. ${ }^{[18]}$ advised double plating in highly unstable fracture. Bolhofner et al. ${ }^{[19]}$ suggested use of composite fixation (lateral plate with medial external fixator) in patient with extraarticular proximal tibia fracture.

In present study only inter fragmentary screws were used as additional technique in 1/7 patients of Group II.

In present study rate of mal union was higher in Group I treated with IMN as compared to the Group II treated with PTP $14.8 \%$ (1/7) cases develop malunion in followup. This study reported that malunion is more prevalent in the sagittal plane than the coronal plane for both implants. $(3,4,10,11$, 12)

Table 4: Comparison of infection rate in various studies

\begin{tabular}{|c|c|c|}
\hline Study & IMN group & PTLCP group \\
\hline Bhandari et al. ${ }^{[20]}$. & $2.5 \%$ & $14 \%$ \\
\hline Lindvall et al. ${ }^{[13]}$. & $28 \%$ & $24 \%$ \\
\hline Oh C W. et al. ${ }^{[18]}$. & $0 \%$ & - \\
\hline Present Study & 7.14 & 28.5 \\
\hline
\end{tabular}

Over all higher rate of infection in PTLCP group may be attributable to large incision, soft tissue damage, shortcomings in addressing these soft tissue injuries, additional co morbidities.

In various studies of extra articular proximal tibia fractures treated with IMN, full weight bearing has ranged from 8-16 weeks depending upon the fracture location, fracture pattern and surgeon preference ${ }^{[13,5]}$. Studies often state "weight bearing advanced as tolerated" but this does not accurately define when full weight bearing actually occurred and therefore can't be used to determine if either technique allow for earlier full weight bearing without implant failures.

Unfortunately present study could not document the benefit of either of the treatment modality in this parameter.

Table 5: Comparison of nonunion rate in various studies

\begin{tabular}{|c|c|c|}
\hline Study & IMN & Plate \\
\hline Bhandari et al. ${ }^{[20]}$. & $3.51 \%(7 / 199)$ & $1.35 \%(1 / 74)$ \\
\hline Lindvall et al. $^{[13]}$. & $23 \%(5 / 22)$ & $6 \%(2 / 34)$ \\
\hline Present study & $7.14 \%(1 / 14)$ & $0 \%(0 / 7)$ \\
\hline
\end{tabular}

Distraction, lack of cortical contact, soft tissue interposition, poor vascular supply, persistent high grade infection or excessive mal alignment at the fracture site may be the causative factors for nonunion after fixation in patients treated with IMN, while soft tissue interposition, persistent deep high grade infection seems to be responsible for nonunion in patients treated with PTLCP. Overall pooled rate of nonunion was low, in intramedullary nailing (1/14) $7.14 \%$ and plating $(0 / 7) 0 \%$.

Over all mean union time was 17.15 weeks. Mean union time in Group 1 was 16.2 weeks (range 14-24 weeks) while mean union time in Group II is 18.1 weeks (range 16-22 weeks). 


\section{Conclusion}

This prospective comparative study concludes that in treatment of proximal tibia extra articular fracture use of IMN and PTLCP gives comparable results. Use of PTLCP is associated with more intra operative blood loss, higher postoperative infection rate and longer duration of hospital stay whereas use of IMN associated with higher rates of malunion and nonunion. However there is no difference in functional outcome between IMN and PTLCP. To validate this issue further a large sample size multi centric study is recommended. Overall proximal one third extraarticular tibia fracture is complicated and problematic fracture to deal with and is commonly associated with significant soft tissue damage. High grade of surgical skills are required to deal these fractures as fixation of proximal one third extraarticular tibia fracture is technically demanding surgery regardless of the implant.

\section{References}

1. Court-Brown CM, McBirnie J. The epidemiology of tibial fractures. J Bone Jt Surg Br. 1995; 77(3):417-421

2. Freedman EL, Johnson EE. Radiographic analysis of tibial fracture malalignment following intramedullary nailing. Clin Orthop Relat Res. 1995; 315:25-33

3. DeCoster TA, Nepola JV, el-Khoury GY. Cast brace treatment of proximal tibia fractures. A 10-year followup study. Clin Orthop Relat Res. 1988; 231:196204

4. Milner SA, Davis TR, Muir KR, Greenwood DC, Doherty M. Long-term outcome after tibial shaft fracture: is malunion important? J Bone Jt Surg Am. 2002; 84$\mathrm{A}(6)$ :971-980

5. Nork SE, Barei DP, Schildhauer TA, Agel J, Holt SK, Schrick JL, et al. Intramedullary nailing of proximal quarter tibial fractures. J Orthop Trauma. 2006; 20(8):523-528

6. Bhandari M, Audige L, Ellis T. Operative treatment of extraarticular proximal tibial fractures. J Orthop Trauma. 2003; 17(8):591-595

7. Lindvall E, Sanders R, Dipasquale T, Herscovici D, Haidukewych G, Sagi C. Intramedullary nailing versus percutaneous locked plating of extra-articular proximal tibial fractures: comparison of 56 cases. J Orthop Trauma. 2009; 23:485-492

8. Naik MA, Arora G, Tripathy SK, Sujir P, Rao SK. Clinical and radiological outcome of percutaneous plating in extra-articular proximal tibia fractures: a prospective study. Injury. 2013; 44(8):1081-1086

9. Freedman EL, Johnson EE. Radiographic analysis of tibial fracture malalignment following intramedullary nailing. Clin Orthop Relat Res. 1995; 315:25-33

10. Schutz M, Kaab MJ, Haas N. Stabilization of proximal tibia fractures with the LIS-System: early clinical experience in Berlin. Injury. 2003; 34(1):A30-A35. Doi: 10.1016/S0020-1383(03)00255-9

11. Cole PA, Zlowodzki M, Kregor PJ. Treatment of proximal tibia fractures using the less invasive stabilization system: surgical experience and early clinical results in 77 fractures. J Orthop Trauma. 2004; 18(8):528-35. Doi: 10.1097/00005131-200409000-00008

12. Cole PA, Zlowodzki M, Kregor PJ. Treatment of proximal tibia fractures using the less invasive stabilization system: surgical experience and early clinical results in 77 fractures. J Orthop Trauma. 2004; 18(8):528-35. Doi:10.1097/00005131-200409000-00008

13. Lindvall E, Sanders R, Dipasquale T, Herscovici D,
Haidukewych G, Sagi C. Intramedullary nailing versus percutaneous locked plating of extra-articular proximal tibial fractures: comparison of 56 cases. J Orthop Trauma. 2009; 23:485-92. doi:10.1097/BOT.0b013e3181 b013d2

14. Beuhler KC, Green J, Woll TS, Duwelius PJ. A technique for intramedullary nailing of proximal third tibia fractures. J Orthop Trauma. 1997; 11(3):218-23. Doi: 10.1097/00005131-199704000-00014

15. Lang GJ, Cohen BE, Bosse MJ, Kellam JF. Proximal third tibial shaft fractures. Should they be nailed? Clin Orthop Relat Res. 1995; 315:64-74

16. Nork SE, Barei DP, Schildhauer TA, Agel J, Holt SK, Schrick JL, et al. Intramedullary nailing of proximal quarter tibial fractures. J Orthop Trauma. 2006; 20(8):523-28. doi:10.1097/01.bot.0000244993.60374.d6.

17. Tornetta P, Collons E. Semiextended position of intramedullary nailing of the proximal tibia. Clin Orthop Relat Res. 1996; 328:185-9. Doi: 10.1097/00003086-199 607000-00029.

18. Oh CW, Oh JK, Kyung HS, Jeon IH, Park BC, Min WK, et al. Minimally Invasive Percutaneous Plate Osteosynthesis Of Proximal Tibial Fractures Using Locking Compression Plate - A Prospective Study. Acta Orthopaedica [Acta Orthop], ISSN: 1745-3674, 2006; 77(3):524-30;

19. Bolhofner BR. Indirect reduction and composite fixation of extraarticular proximal tibial fractures. Clin Orthop Relat Res. 1995; 315:75-83

20. Bhandari M, Audige L, Ellis T. Operative treatment of extraarticular proximal tibial fractures. J Orthop Trauma. 2003; 17(8):591-5. Doi: 10.1097/00005131-20030900000013 